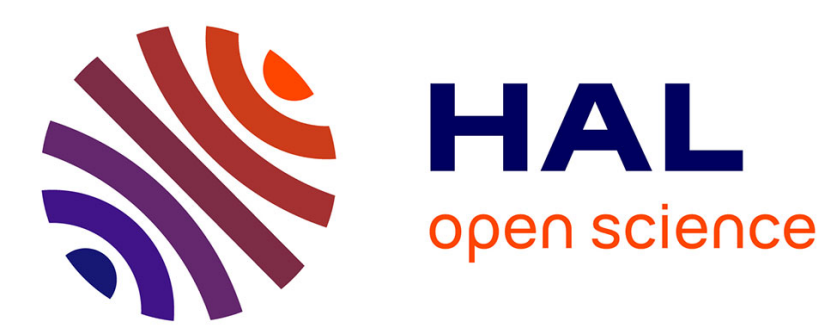

\title{
Time Resolved Spectroscopy of RF Plasmas: A Comparison of Hydrogen and Deuterium Plasmas
}

\author{
W. Graham, C. Mahony
}

\section{To cite this version:}

W. Graham, C. Mahony. Time Resolved Spectroscopy of RF Plasmas: A Comparison of Hydrogen and Deuterium Plasmas. Journal de Physique IV Proceedings, 1997, 07 (C4), pp.C4-209-C4-214. 10.1051/jp4:1997416 . jpa-00255572

\section{HAL Id: jpa-00255572 https://hal.science/jpa-00255572}

Submitted on 1 Jan 1997

HAL is a multi-disciplinary open access archive for the deposit and dissemination of scientific research documents, whether they are published or not. The documents may come from teaching and research institutions in France or abroad, or from public or private research centers.
L'archive ouverte pluridisciplinaire HAL, est destinée au dépôt et à la diffusion de documents scientifiques de niveau recherche, publiés ou non, émanant des établissements d'enseignement et de recherche français ou étrangers, des laboratoires publics ou privés. 


\title{
Time Resolved Spectroscopy of RF Plasmas: A Comparison of Hydrogen and Deuterium Plasmas
}

\author{
W.G. Graham and C.M.O. Mahony
}

Department of Pure and Applied Physics, The Queen's University of Belfast, Belfast BT7 INN, Northern Ireland

\begin{abstract}
Spatio-temporal resolved emission is a powerful technique for exploring the neutral, ionic and electron characteristics of if driven plasmas. Here this is illustrated by measurements of emission from capacitively coupled $\mathrm{H}_{2}$ and $\mathrm{D}_{2}$ if driven plasmas. These exhibit two pronounced emission regions, one associated with the normal sheath edge and the other near the driven electrode. Timeresolved electrode and plasma potential measurements show this near-electrode emission is associated with field reversal in the electrode sheath. The close similarity of the emission structure in the two isotopes, and the general lack of such structure in He plasmas indicates that the structure and hence field reversal are not solely due to ion mass effects but may also involve the details of the electron collisionality of the gas.
\end{abstract}

\section{INTRODUCTION}

Visual observation of a typical if plasma provides the most obvious plasma diagnostic tool. For example, from an observation of change of the colour or the spatial variation in intensity experienced operators can diagnose a vacuum leak or a change in the character of a surface. Often such colour or intensity changes occur immediately after ignition or after a change of operating conditions or substrate. However the emission of light is a complex process depending on the detailed chemical and physical nature of the plasma and so can reveal much more detailed information. The abundance of atomic and molecular species in the ambient gas and its plasma products in the ground and excited states influence the emission. Most emission occurs as a result of collisions of the atom or molecule with an electron, so the electron density and energy distributions are important. Carefully designed experiments can therefore provide detailed information about these plasma species and parameters. Here the emphasis will be on the observation of plasma emission to study the behaviour of plasma electrons.

By observing only light at a wavelength specific to a particular constituent species and under conditions were it can be assumed that the density of that species is spatially and temporally uniform, the emission is indicative of the behaviour of the electrons exciting that species. In if driven plasmas the electrons may be modulated with the frequency of the electrode voltage. In most technological plasmas this frequency is $13.56 \mathrm{MHz}$ i.e. a period of $73.7 \mathrm{~ns}$. Fast photon counting techniques allow emission intensity variation measurements with a resolution in the nanosecond region, permitting a study of the high energy portion of the electron energy distribution through the if cycle. There have been many previous studies of spatio-temporal resolved measurements of emission from such plasmas [1-12]. We have exploited the fast gating ( $<2 \mathrm{~ns}$ ) capabilities of recently available ICCD detectors to study emission. Since the plasma can be imaged onto the detector array, this greatly facilitates spatially resolved measurements. In our previously reported measurements we have compared and contrasted spatio-temporal emission of $\mathrm{H}_{2}, \mathrm{He}$ and Ar atoms $[13,14]$. The most obvious difference in the excitation data from the three gases was the prominent double emission structure observed in $\mathrm{H}_{2}$. Such emission structure has previously been reported in $\mathrm{H}_{2}$ and $\mathrm{H}_{2}$-containing gas mixtures [6,7,10,12-17]. 
A number of mechanisms to explain the inner near-electrode emission layer have been advanced. These include electrons propagating from the electrode [10] and electric field reversal for a portion of the if cycle [15]. The latter involves the presence of structure in the sheath electric field i.e. a change in electric field direction over a certain region. Several authors [18-20] have reported measurements of field reversal within if sheaths in $\mathrm{Ar}$ and $\mathrm{He}$ but not specifically associated with double emission layers. Many if sheath models predict a change in electric field direction when the sheath is contracting [18, 21-25]. While in general little attention has been given to these features they were recently seen as evidence of sheath reversal and subsequent plasma heating during sheath contraction in an rf driven nitrogen plasma [24]. Therefore we additionally measured the time dependence of the electrode-plasma potential difference correlated with the time dependence of excitation through the of cycle $[13,14]$. These measurements showed that, in contrast to $\mathrm{He}$ and $\mathrm{Ar}$, in $\mathrm{H}_{2}$ the electrode goes positive with respect to the plasma i.e. there is a period during the if cycle when electrons are accelerated towards the electrode. This electric field reversal is at that phase of the if cycle where the near electrode emission in $\mathrm{H}_{2}$ occurs.

The physical process that leads to this electric field reversal is not yet clear. We felt our measurements supported a postulate that it arose from the relatively high electron collision rate in hydrogen, others have associated this effect with the lighter ion mass of hydrogen or the presence of negative ions. In preliminary ion mass studies we noted almost identical behaviour in $\mathrm{H}_{2}$ and $\mathrm{D}_{2}$ [13]. In an attempt to throw further light on this issue here we report a more detailed study of plasmas with the two hydrogen isotopes.

\section{EXPERIMENTAL DETAILS}

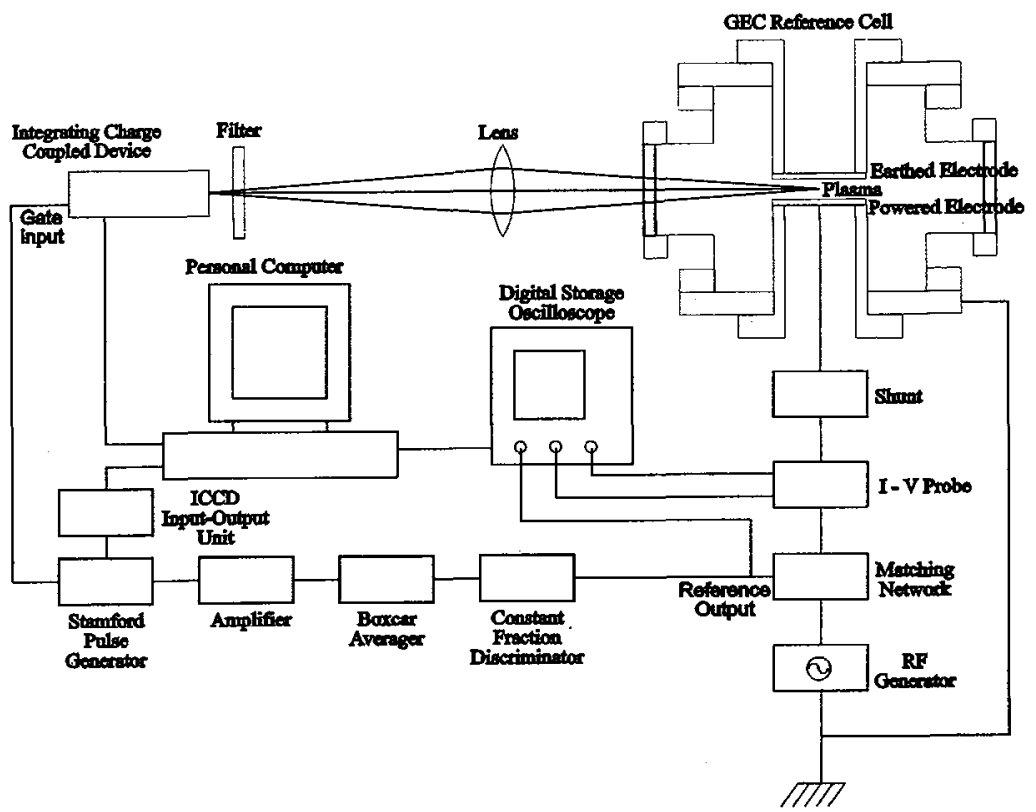

Figure 1: A schematic diagram of the apparatus

A schematic diagram of the plasma and optical emission systems are shown in Fig. 1. The present measurements were made in the UK GEC (Gaseous Electronics Conference) if reference reactor [26]. This is a parallel plate device with two $102 \mathrm{~mm}$ diameter electrodes separated by $25.4 \mathrm{~mm}$. The upper, aluminium electrode and the stainless steel vacuum vessel were grounded. The plasma was created by capacitively coupling if voltages at $13.56 \mathrm{MHz}$, to the lower, stainless steel electrode. In the present 
measurements peak-to-peak if voltages of up to $1200 \mathrm{~V}$ were applied producing plasma input powers of up to $150 \mathrm{~W}$ and discharge currents of up to $3 \mathrm{~A}$. The operating pressures, ranging from 33 to $133 \mathrm{~Pa}$ ( 250 to $1000 \mathrm{mTorr}$ ), were measured using a capacitance manometer.

Time resolved light emission measurements were obtained by imaging the central plasma onto an Oriel Instruments Instaspec $\mathrm{V}$ fast-gated integrating charge coupled device (ICCD). A lens with a focal length of $200 \mathrm{~mm}$ and aperture $f 4.5$, placed $250 \mathrm{~mm}$ from the ICCD and $1.1 \mathrm{~m}$ from the plasma centre was used. This imaged a vertical section of the plasma region, which inciuded both the electrodes, and a horizontal section which extended $\sim 15 \mathrm{~mm}$ either side of the central axis. A $657 \mathrm{~nm}$ filter with a HWHM bandpass of $11 \mathrm{~nm}$ was used to select the $656 \mathrm{~nm}$ Balmer- alpha line of $\mathrm{H}_{2}$ and $\mathrm{D}_{2}$.

The depth of field of the image represented $18 \mathrm{~mm}$ of the central plasma region. Vignetting of the image by the electrodes was a small effect in the present measurements. The collection angle of the lens was effectively constant except within $0.5 \mathrm{~mm}$ of either electrode, dropping linearly to about $80 \%$ of the central value at the electrode. The spatial resolution was $0.5 \pm 0.1 \mathrm{~mm}$, determined by comparison with a test image.

The ICCD gate was triggered by the output of a delayed pulse generator which was triggered by a pulse derived from a reference waveform from the matching unit. Software automatically incremented the pulse delay by 2 ns to record data for the next gating step, and the process was repeated until 75 delay steps ( $150 \mathrm{~ns}$ ) had been completed, i.e. two complete if cycles. The time and space resolved images were accumulated within $120 \mathrm{~s}$. The accuracy of the gating pulse with respect to the phase of the matching network reference signal was determined to be $\pm 0.3 \mathrm{~ns}$.

The time variation of the light emission intensity $I(t)$ was measured but it is the time dependence of the excitation $E(t)$ which reflects the time-dependent behaviour of the electrons, $I(t)$ is related to $E(t)$ via a convolution integral [2]. Here the measured emission signal $I(t)$ is deconvoluted with the radiative lifetime of the excited state (15 ns) to give the excitation $\mathrm{E}(\mathrm{t})$. In hydrogen we neglect quenching which introduces at most an uncertainty of $1 \mathrm{~ns}$ in timing $[10,16]$. The self quenching rate for deuterium will be slower.

The time varying electrode potential relative to the plasma was obtained from dc and ac measurements of the electrode and the plasma potentials [13]. The time-averaged and ac components of plasma potential were measured using a passively compensated Langmuir probe and a capacitive probe respectively. The Langmuir probe was also used to measure time-averaged plasma parameters such as electron density and temperature. The dc component of the electrode potential was recorded directly from the rf matching unit. We used a derivative probe and shunt to determine time resolved electrode potentials (time resolved plasma currents were also recorded by this technique).

To reduce noise our instruments employ averaging over a number of cycles for these optical and electrical measurement techniques so cycle to cycle variation would not be apparent. Never the less single shot measurements of the ac component of electrode current and potential shows only random cycle to cycle variation of $\sim 1 \%$ with no significant contribution from sub harmonics.

\section{RESULTS AND DISCUSSION}

The Langmuir probe measurements indicate that the electron density in $\mathrm{H}_{2}$ plasmas varied from $2 \times 10^{9}$ to $3 \times 10^{10} \mathrm{~cm}^{-3}$ for the present pressure and power conditions. The measured electron densities in $\mathrm{D}_{2}$ were generally about $50 \%$ lower. The kinetics of hydrogen plamsas are complicated and no self-constitent numerical model exists for if plasmas. For example the plasma contains three types of positive ions $\mathrm{H}^{+}, \mathrm{H}_{2}{ }^{+}$ and $\mathrm{H}_{3}{ }^{+}$but their relative concentration has, to our knowledge, not been measured or calaculated. While $\mathrm{H}_{2}{ }^{+}$is created directly by electron impact ionisation of the $\mathrm{H}_{2}$ molecules they can be rapidly converted to $\mathrm{H}_{3}^{+}$by

$$
\mathrm{H}_{2}^{+}+\mathrm{H}_{2} \rightarrow \mathrm{H}_{3}^{+}+\mathrm{H}
$$

which has a very large cross section for low energy $\mathrm{H}_{2}^{+}\left(>3 \times 10^{-15} \mathrm{~cm}^{2}\right.$ for $\mathrm{E}<0.1 \mathrm{eV}$ [27]). Since the dissociation fraction in capacitively coupled plasmas is relatively low $\sim 0.005$ [28] and protons are produced mainly from the direct ionisation of atoms they are probably the minority ionic species. The densities of the three ionic species are strongly coupled and will vary with plasma conditions and with 
isotope. Models of $\mathrm{H}_{2}$ glow discharges have to date assumed a single $\mathrm{H}_{2}^{+}$species [12]. This lack of information makes it difficult to accuratley determine the ion response to the if fields. Using the measured electron densities and assuming the diatomic ion is dominant then the ion plasma frequency is expected to vary from $9 \mathrm{MHz}$ to $33 \mathrm{MHz}$ in $\mathrm{H}_{2}$ and from $4 \mathrm{MHz}$ to $16 \mathrm{MHz}$ in $\mathrm{D}_{2}$. If the triatomic ion is dominant then the values are $5 \mathrm{MHz}$ to $20 \mathrm{MHz}$ in $\mathrm{H}_{2}$ and from $3.5 \mathrm{MHz}$ to $13 \mathrm{MHz}$ in $\mathrm{D}_{2}$.

0

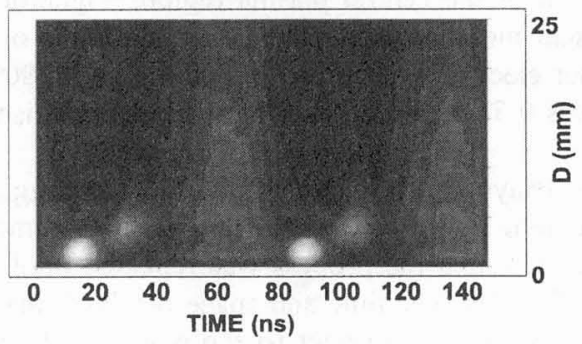

$\mathbf{0}$
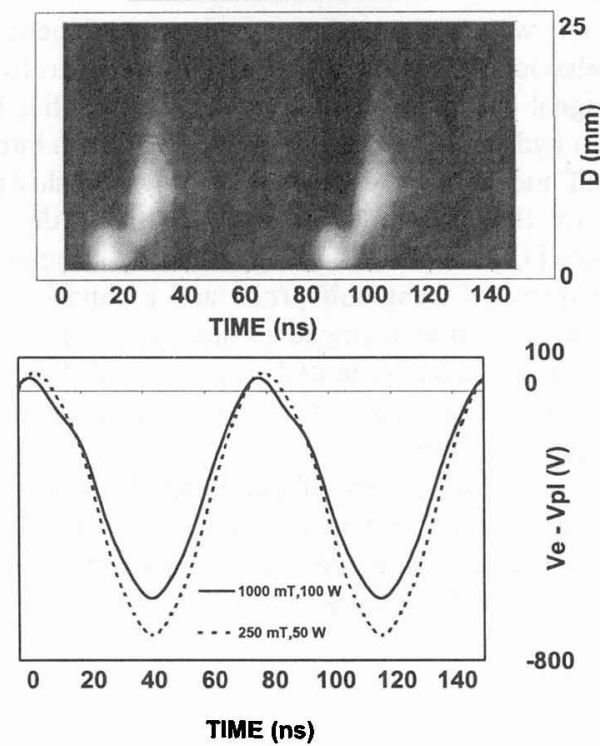

0 50000
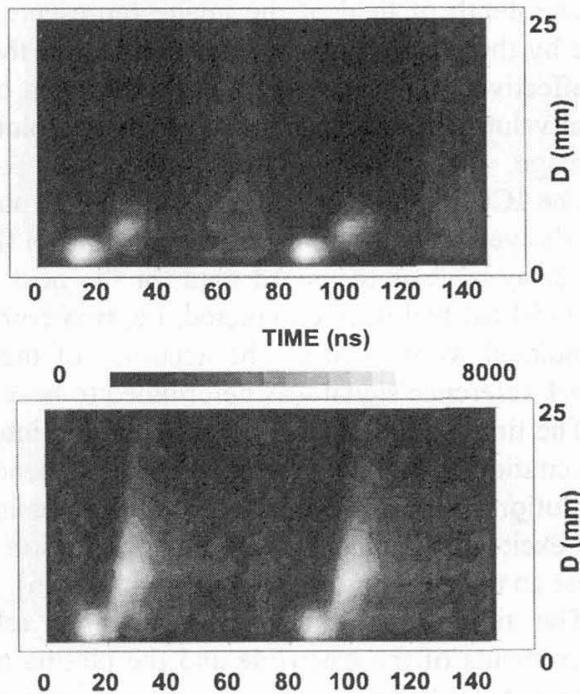

TIME (ns)

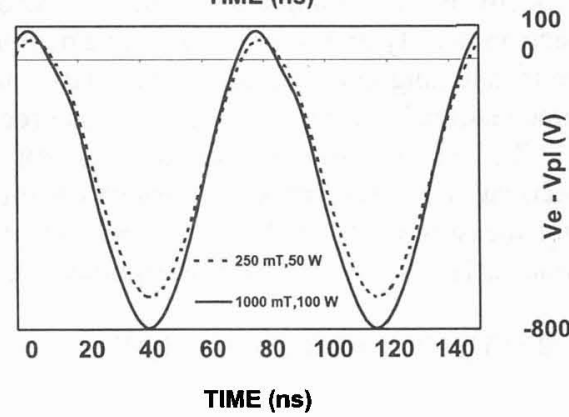

Figure 2. Spatially and temporally resolved Balmer alpha Figure 3. Spatially and temporally resolved Balmer alpha excitation from a hydrogen plasma operating with a forward excitation from a deuterium plasma operating with a directed if power of $50 \mathrm{~W}$ and gas pressure 250 mTorr (top) forward directed if power of $50 \mathrm{~W}$ and gas pressure 250 and $100 \mathrm{~W}$ and 1000 mTorr (middle). The temporal mTorr (top) and $100 \mathrm{~W}$ and 1000 mTorr (middle). The dependence of the driven electrode potential relative to the temporal dependence of the driven electrode potential plasma under the same conditions (bottom). relative to the plasma under the same conditions (bottom).

The space and time resolved excitation data for Balmer-alpha excitation typical of those obtained in $\mathrm{H}_{2}$ and $\mathrm{D}_{2}$ are shown in Figs 2 and 3 respectively. The threshold energy for exciting this state from the $\mathrm{H}_{2}$ ground state is $16.6 \mathrm{eV}$. This is probably the dominant mechanism since the dissociation fraction is low. 
The results for both $\mathrm{H}_{2}$ and $\mathrm{D}_{2}$ are very similar. While the potentials are slightly different the near electrode excitation is seen to occur after the electrode is at its least negative with respect to the plasma. The strong positive peaks in the electrode current waveforms occur at this time. In both cases the electrode is positive with respect to the plasma, indicating a sheath collapse. This is a period during the if cycle when electrons are accelerated towards the electrode, causing excitation of, and subsequent emission from, gas atoms in the near electrode region. This is an important observation since it appears to invalidate the argument that the near-electrode emission is an ion mass effect. The ion mass effect has been studied in fluid and PIC-MC models[12]. These correctly predicted the emission structure in hydrogen, using $\mathrm{H}_{2}{ }^{+}$as the dominant ion. No calculations have to date been made for $D_{2}$. Helium would have the same or intermediate ionic mass to $D_{2}$ depending on which ion state is dominant. The models shows no evidence of near-electrode emission which is largely consistent with our measurements in He[14]. In our helium measurements the only indications of near-electrode emission are at lower pressures and highest powers where associated sheath collapsed is also observed in our potential measurements.

The close similarity of the two emission region structure in the $\mathrm{H}_{2}$ and $\mathrm{D}_{2}$, and general lack of such structure in He plasmas indicates that the structure and hence field reversal are not solely due to ion mass effects but also involves the details of the atomic structure of the gas.

\section{Acknowledgements}

This work was supported by the UK Engineering and Physical Science Research Council.

\section{References}

[1] Barnes R. M. and Winslow R. J., J. Phys. Chem., 82 (1978) 1869.

[2] de Rosny V., Mosburg E.R., Abelson J.R., Devaud G. and Kerns R.C., J. Appl. Phys. 54 (1983) 2272.

[3] Donnelly V.M., Flamm D.L. and Bruce R.H., J. Appl. Phys. 58 (1985) 2135.

[4] Bletzinger P. and de Joseph Jnr C. A., IEEE Trans. Plasma Sci. PS-14 (1986)124.

[5] Flamm D.L. and Donnelly V.M., J. Appl. Phys. 59 (1986) 1052.

[6] Tochikubo F., Suzuki A., Kakuta S., Terazono Y. and Makabe T., J. Appl. Phys. 68 (1990) 5532.

[7] Tochikubo F., Kokubo T., Kakuta S., Suzuki A. and Makabe T., J. Phys. D, 23 (1990) 1184.

[8] Koehler W.E., Seeboeck R. J. and Rebentrost F., J. Phys. D: Appl. Phys. 24 (1991) 252.

[9] Shimozuma M., Tochitani G. and Tagashira H., J.Appl. Phys. 70 (1991) 645.

[10] Tochikubo F., Makabe T., Kakuta S. and Suzuki A., J. Appl. Phys. 71 (1992) 2143.

[11] Djurovic S., Roberts J.R., Sobolewski M.A. and Olthoff J.K., J. Res. Natl. Inst. Stand. Technol. 98 (1993) 159.

[12] Leroy O., Stratil P., Perrin J., Jolly J. and Belenguer P., J. Phys. D: Appl. Phys., 28 (1995) 500.

[13] Mahony C.M.O., Al Wazzan R. and Graham W.G.,Appl. Phys. Lett. 71 (1997) 608.

[14] Graham W.G. and Mahony C.M.O., "Experimental studies of rf sheaths." Proc. NATO ARW on

Kinetic modelling of if discharges (Plenum Publishing. to be published).

[15] Mutsukara N., Koyabashi K. and Machi Y., J. Appl. Phys. 66 (1989) 468.

[16] Kakuta S., Kitajima T., Okabe Y. and Makabe T., Jpn. J. Appl. Phys., 33 (1994) 4335.

[17] Radovanov S.B., Dzierzega K., Roberts J.R. and Olthoff J.K., Appl. Phys. Lett., 66 (1995) 263.

[18] Sato A. and Lieberman M.A., J. Appl. Phys., 68 (1990) 6117.

[19] Ruzik D.N. and Wilson J.L.,_J. Vac. Sci. \& Technol, A8 (1990) 3746.

[20] Okuno Y. and Fujita H.J., Appl. Phys., 70 (1991) 642.

[21] Sommerer T.J., Hitchon W.N.G. and Lawler J.E., Phys. Rev. Lett., 63 (1989) 2361.

[22] Sommerer T.J., Hitchon W.N.G., Harvey R.E.P. and Lawler J.E., Phys. Rev. A., 43 (1991) 4552.

[23] Surendra M. and Graves D.B., Phys. Rev. Lett., 66 ,1469 (1991) and IEEE Trans. Plasma Sci., 19 (1991) 144 . 
[24] Turner M.M. and Hopkins M.B., Phys. Rev. Lett., 69 (1992) 3511.

[25] Vender D. and Boswell R.W., J. Vac. Sci. Technol., A10 (1992) 331.

[26] Hargis Jr. P.J., Greenberg K.E., Miller P.A., Gerardo J.B., Torczymski J.R., Roley M.E., Hebner G.A., Roberts J.R., Olthoff J.K., Whetstone J.R., Van Brunt R.J., Sobolewski M.M., Anderson H.M., Splichal M.P.,Mock J.L. Bletzinger P., Garscadden A., Gottscho R.A., Selwyn G., Dalvie M., HeidenreichJ .E., Bitterbaugh J. W., Brake M.L., Passov M. L., PenderJ., Lujan A., Elta M.E., Graves D.B., Sawin H.H., Kushner M.J., Verdeyen. T., Horwath R. and Turner T.R. , Rev. Sci. Instrum. 65 (1994) 140.

[27] Neynaber R.H. and Trujillo S.M., Phys. Rev. 167 (1968) 63.

[28] Tserepi A.D., Dunlop J.R., Preppernau B.L. and Miller T.A., J.Appl. Phys. 72 (1992) 2838. 